Article

\title{
In Vitro Metabolic Pathways of the New Anti-Diabetic Drug Evogliptin in Human Liver Preparations
}

\author{
Hyeon-Uk Jeong ${ }^{1}$, Ju-Hyun Kim ${ }^{1}$, Dae Young Lee ${ }^{2}$, Hyun Joo Shim ${ }^{2}$ and Hye Suk Lee ${ }^{1, *}$ \\ Received: 3 November 2015 ; Accepted: 25 November 2015 ; Published: 4 December 2015 \\ Academic Editor: Derek J. McPhee \\ 1 Drug Metabolism and Bioanalysis Laboratory, College of Pharmacy, The Catholic University of Korea, \\ Bucheon 420-743, Korea; wjd1375@hanmail.net (H.-U.J.); jhyunkim@catholic.ac.kr (J.-H.K.) \\ 2 Research Center, Dong-A ST Co., Yongin 446-905, Korea; dylee@donga.co.kr (D.Y.L.); \\ shimhj@donga.co.kr (H.J.S.) \\ * Correspondence: sianalee@catholic.ac.kr; Tel.: +82-2-2164-4061; Fax: +82-32-342-2013
}

\begin{abstract}
Evogliptin ((R)-4-((R)-3-amino-4-(2,4,5-trifluorophenyl)butanoyl)-3-(tert-butoxymethyl)piperazin-2-one), is a new dipeptidyl peptidase IV inhibitor used for the treatment of type II diabetes mellitus. The in vitro metabolic pathways of evogliptin were identified in human hepatocytes, liver microsomes, and liver S9 fractions using liquid chromatography-Orbitrap mass spectrometry (LC-HRMS). Five metabolites of evogliptin-4-oxoevogliptin (M1), 4(S)-hydroxyevogliptin (M2), 4(R)-hydroxyevogliptin (M3), 4(S)-hydroxyevogliptin glucuronide (M4), and evogliptin N-sulfate (M5) - were identified in human liver preparations by comparison with authentic standards. We characterized the cytochrome P450 (CYP) enzymes responsible for evogliptin hydroxylation to 4(S)-hydroxyevogliptin (M2) and 4(R)-hydroxyevogliptin (M3) and the UGT enzymes responsible for glucuronidation of 4(S)-hydroxyevogliptin (M2) to 4(S)-hydroxy-evogliptin glucuronide (M4). CYP3A4/5 played the major role in the hydroxylation of evogliptin to 4(S)-hydroxyevogliptin (M2) and 4(R)-hydroxyevogliptin (M3). Glucuronidation of 4(S)-hydroxy-evogliptin (M2) to 4(S)hydroxyevogliptin glucuronide (M4) was catalyzed by the enzymes UGT2B4 and UGT2B7. These results suggest that the interindividual variability in the metabolism of evogliptin in humans is a result of the genetic polymorphism of the CYP and UGT enzymes responsible for evogliptin metabolism.
\end{abstract}

Keywords: evogliptin metabolism; human hepatocytes; cytochrome P450; UDP-glucuronosyltransferases

\section{Introduction}

Type II diabetes mellitus (DM) is a chronic metabolic disorder, characterized by relative insulin deficiency due to disorders of insulin secretion and insulin resistance, the prevalence of which has increased continually in the majority of countries [1]. Various classes of oral antidiabetic drugs can be used to control the blood glucose level and to prevent diabetic complications such as diabetic nephropathy and retinopathy [1,2].

Dipeptidyl peptidase IV (DPP-IV) inhibitors reduce the blood glucose level by inhibiting DPP-IV, a ubiquitous enzyme which rapidly degrades glucagon-like peptide 1 and glucose-dependent insulinotropic polypeptide, and many DPP-IV inhibitors-including alogliptin, anagliptin, gemigliptin, linagliptin, saxagliptin, sitagliptin, teneligliptin, and vildagliptin-have been developed as oral antihyperglycemic agents for the treatment of type II DM [1-5].

Evogliptin (DA-1229, trade name: Sugarnon ${ }^{\circledR}$ ), a new, potent, and selective DPP-IV inhibitor [6-11], was approved by the Ministry of Food and Drug Safety of Korea as an oral antihyperglycemic drug for the treatment of type II DM on October 22015. Although the pharmacokinetic properties of evogliptin 
in humans have been reported $[9,10]$, there is no report of its in vitro metabolism in humans. Metabolite identification and characterization of drug-metabolizing enzymes-such as cytochrome P450 (CYP) and UDP-glucuronosyltransferase (UGT) - responsible for the metabolism of drugs can facilitate prediction of interindividual variations in drug metabolism and pharmacokinetics, together with drug-drug interactions [12-14]. The purposes of the present study were to identify the metabolites of evogliptin formed after incubation with human hepatocytes, liver microsomes, and liver S9 fractions in the presence of cofactors using liquid chromatography-Orbitrap mass spectrometry (LC-HRMS), and to characterize the CYP and UGT enzymes responsible for evogliptin metabolism.

\section{Results and Discussion}

\subsection{In Vitro Metabolic Profiles of Evogliptin in Human Hepatocytes, Liver Microsomes, and Liver S9 Fractions}

LC-HRMS analysis following incubation of evogliptin with human hepatocytes resulted in the formation of five evogliptin metabolites M1-M5 (Figure 1A). Following incubation of evogliptin with liver S9 fractions in the presence of NADPH and PAPS, three metabolites-M2, M3 and M5-were identified by LC-HRMS (Figure 1B). The retention time ( $\left.t_{R}\right)$ and accurate mass of protonated or deprotonated molecular ions $\left([\mathrm{M}+\mathrm{H}]^{+}\right.$or $\left.[\mathrm{M}-\mathrm{H}]^{-}\right)$and the characteristic fragment ions for evogliptin and five metabolites (M1-M5) are summarized in Table 1.

(A)

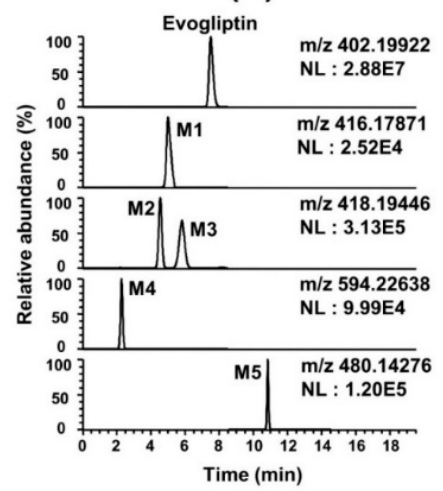

(C)

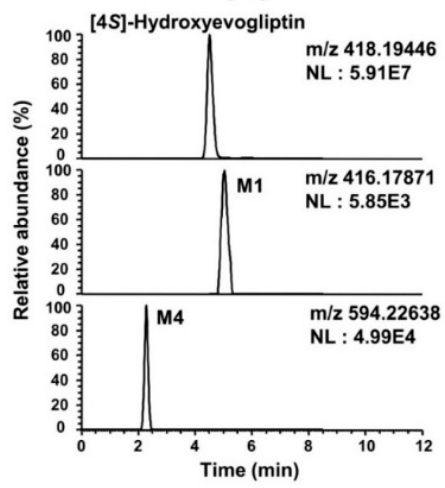

(B)

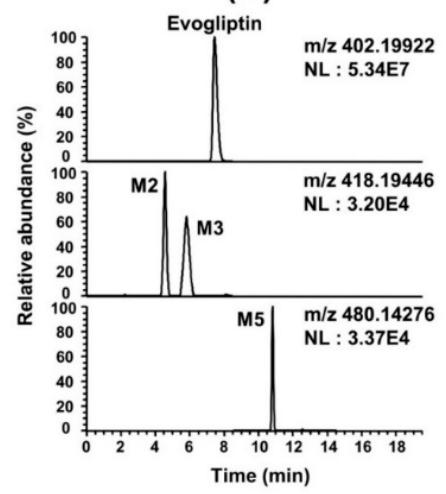

(D)

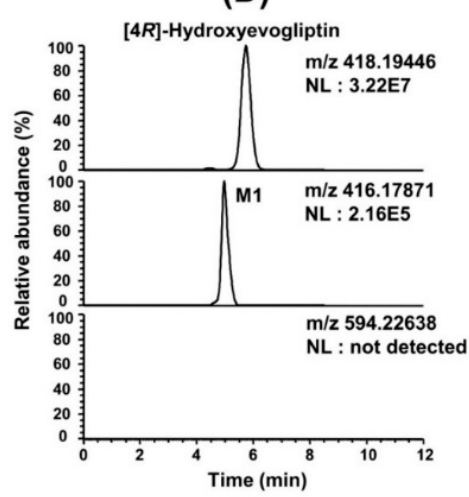

Figure 1. (A) Extracted ion chromatograms (EIC) of evogliptin and possible metabolites after incubation of evogliptin with human hepatocytes; (B) EIC of evogliptin and possible metabolites after incubation of evogliptin with pooled human liver S9 fractions in the presence of NADPH and PAPS; (C) EIC of 4(S)-hydroxyevogliptin and possible metabolites after incubation of 4(S)-hydroxyevogliptin (M2) with pooled human liver microsomes in the presence of NADPH and UDPGA; and (D) EIC of $4(R)$-hydroxyevogliptin and possible metabolites after incubation of $4(R)$-hydroxyevogliptin (M3) with pooled human liver microsomes in the presence of NADPH and UDPGA. 
Table 1. Retention time and exact mass of the molecular ion of evogliptin and five metabolites identified after incubation of evogliptin with human hepatocytes, liver microsomes, and S9 fractions.

\begin{tabular}{ccccccc}
\hline No. & Compound Name & Formula & $\begin{array}{c}\text { Electrospray } \\
\text { Ionization Mode }\end{array}$ & $\begin{array}{c}\text { Detected Exact } \\
\text { Mass }(\mathbf{m} / \mathbf{z})\end{array}$ & $\begin{array}{c}\text { Error } \\
(\mathbf{p p m})\end{array}$ & $\begin{array}{c}\text { Retention } \\
\text { Time }(\mathbf{m i n})\end{array}$ \\
\hline & Evogliptin & $\mathrm{C}_{19} \mathrm{H}_{26} \mathrm{~F}_{3} \mathrm{~N}_{3} \mathrm{O}_{3}$ & Positive & 402.19922 & -1.7 & 7.51 \\
$\mathrm{M} 1$ & 4-Oxoevogliptin & $\mathrm{C}_{19} \mathrm{H}_{24} \mathrm{~F}_{3} \mathrm{~N}_{3} \mathrm{O}_{4}$ & Positive & 416.17871 & -1.1 & 4.97 \\
$\mathrm{M} 2$ & 4(S)-Hydroxyevogliptin & $\mathrm{C}_{19} \mathrm{H}_{26} \mathrm{~F}_{3} \mathrm{~N}_{3} \mathrm{O}_{4}$ & Positive & 418.19446 & -0.8 & 4.55 \\
$\mathrm{M} 3$ & $4(R)$-Hydroxyevogliptin & $\mathrm{C}_{19} \mathrm{H}_{26} \mathrm{~F}_{3} \mathrm{~N}_{3} \mathrm{O}_{4}$ & Positive & 418.19446 & -0.8 & 5.83 \\
M4 & $4(S)$-Hydroxyevogliptin glucuronide & $\mathrm{C}_{25} \mathrm{H}_{34} \mathrm{~F}_{3} \mathrm{~N}_{3} \mathrm{O}_{10}$ & Positive & 594.22638 & -0.9 & 2.27 \\
M5 & Evogliptin N-sulfate & $\mathrm{C}_{19} \mathrm{H}_{26} \mathrm{~F}_{3} \mathrm{~N}_{3} \mathrm{SO}_{6}$ & Negative & 480.14276 & 1.3 & 10.85 \\
\hline
\end{tabular}

Five metabolites, M1-M5, were identified by comparison with the retention time and fragment ions of the corresponding authentic standards. The product scan spectrum of evogliptin showed a $[\mathrm{M}+\mathrm{H}]^{+}$ion at $\mathrm{m} / \mathrm{z} 402.19942$ with characteristic fragment ions at $\mathrm{m} / \mathrm{z} 346.13704$ (loss of a tert-butyl group from the $[\mathrm{M}+\mathrm{H}]^{+}$ion), $\mathrm{m} / \mathrm{z} 328.12633$ (loss of water from $\mathrm{m} / \mathrm{z} 346.13704$ ), and $\mathrm{m} / \mathrm{z} 155.08138$ (loss of 2-(2,4,5-trifluorophenyl)ethanamine from $\mathrm{m} / \mathrm{z}$ 328.12633) (Figure 2).

M1 showed the $[\mathrm{M}+\mathrm{H}]^{+}$ion at $\mathrm{m} / \mathrm{z} 416.17832$, which was $14 \mathrm{amu}$ more than the $[\mathrm{M}+\mathrm{H}]^{+}$ ion of evogliptin, and yielded the product ions at $\mathrm{m} / \mathrm{z} 360.11592$ (loss of a tert-butyl group from the $[\mathrm{M}+\mathrm{H}]^{+}$ion), $m / z 342.10548$ (loss of water from $\mathrm{m} / \mathrm{z} 360.11592$ ), and $m / z 155.08134$ (loss of 2-(2,4,5trifluorophenyl)ethanamine from $\mathrm{m} / \mathrm{z}$ 342.10548) (Figure 2). Incubation of 4(S)-hydroxyevogliptin (M2) and 4(R)-hydroxyevogliptin (M3) with human liver microsomes in the presence of NADPH resulted in the formation of M1 (Figure 1C,D), suggesting that M1 was formed by 4-hydroxylation of evogliptin followed by dehydrogenation. M1 was identified as 4-oxoevogliptin by comparison with the retention time and MS/MS spectrum of the corresponding authentic standard. The peak area of 4-oxoevogliptin (M1) formed from 4(R)-hydroxyevogliptin (M3) was 40-fold higher than that of M1 formed from 4(S)-hydroxyevogliptin (M2) (Figure 1C,D), indicating that 4-oxoevogliptin (M1) was formed mainly from 4(R)-hydroxyevogliptin (M3).

$\mathrm{M} 2$ and $\mathrm{M} 3$ showed a $[\mathrm{M}+\mathrm{H}]^{+}$ion at $\mathrm{m} / z$ 418.19428, which is $16 \mathrm{amu}$ more than $[\mathrm{M}+\mathrm{H}]^{+}$ion of evogliptin, indicating hydroxylation of evogliptin. The product scan spectra of M2 and M3 showed fragment ions at $m / z 362.13162$ (loss of a tert-butyl group from the $[\mathrm{M}+\mathrm{H}]^{+}$ion), $m / z 344.12133$ (loss of water from $\mathrm{m} / \mathrm{z} 362.13162$ ), and $\mathrm{m} / \mathrm{z} 155.08134$ (loss of 2-(2,4,5-trifluorophenyl)ethanamine from $\mathrm{m} / \mathrm{z}$ 344.12133) (Figure 2). M2 and M3 were identified as 4(S)-hydroxyevogliptin (M2) and $4(R)$-hydroxyevogliptin (M3), respectively, by comparison with the retention time and MS/MS spectra of the corresponding authentic standards.

M4 showed a $[\mathrm{M}+\mathrm{H}]^{+}$ion at $m / z 594.22570$, which is $176 \mathrm{amu}$ higher than the $[\mathrm{M}+\mathrm{H}]^{+}$ion of 4-hydroxyevogliptin, indicating glucuronidation of 4-hydroxyevogliptin. M4 generated characteristic product ions at $m / z 418.19431$ (loss of glucuronic acid moiety from the $[\mathrm{M}+\mathrm{H}]^{+}$ion), $m / z 362.13153$ (loss of a tert-butyl group from $\mathrm{m} / \mathrm{z} 418.19431$ ), $\mathrm{m} / \mathrm{z} 538.16328$ (loss of a tert-butyl group from the $[\mathrm{M}+\mathrm{H}]^{+}$ion), and $\mathrm{m} / \mathrm{z} 155.08129$ (loss of 2-(2,4,5-trifluorophenyl)ethanamine and water from $\mathrm{m} / \mathrm{z}$ 362.13153) (Figure 2). Human liver microsomal incubation of 4(S)-hydroxyevogliptin (M2) in the presence of UDPGA and NADPH resulted in the formation of M4 (Figure 1C). M4 was identified as 4(S)-hydroxyevogliptin glucuronide by comparison with the retention time and MS/MS spectrum of the corresponding authentic standard.

M5 showed a $[\mathrm{M}-\mathrm{H}]^{-}$ion at $\mathrm{m} / \mathrm{z} 480.14220$, which was $80 \mathrm{amu}$ higher than the $[\mathrm{M}-\mathrm{H}]^{-}$ion of evogliptin, indicating sulfation of evogliptin. Since the $[\mathrm{M}+\mathrm{H}]^{+}$ion of $\mathrm{M} 5$ at $\mathrm{m} / \mathrm{z} 482.15646$ showed 195-fold lower peak intensity than that of the $[\mathrm{M}-\mathrm{H}]^{-}$ion of M5, we performed the product scan in negative mode. M5 generated the product ion at $m / z 251.99477$ [(2-(2,4,5-trifluorophenyl)ethylidene) sulfamate ion] (Figure 2). M5 was identified as evogliptin $N$-sulfate by comparison with the retention time and MS/MS spectrum of the authentic standard. N-sulfation of another DPP-IV inhibitor, sitagliptin, in human support that sulfation of evogliptin to M5 in human hepatocytes and liver S9 fractions [15]. 

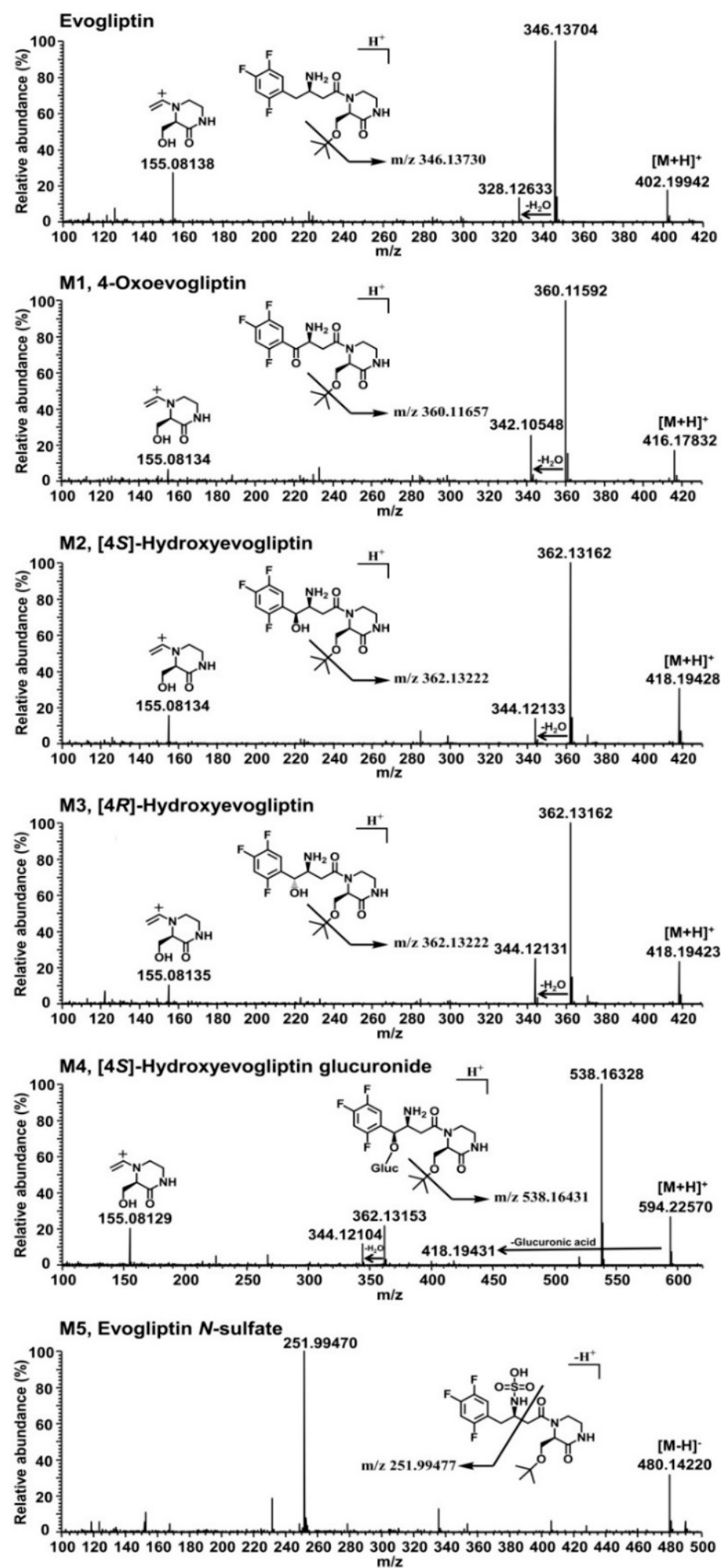

Figure 2. Product scan spectra of evogliptin and the five metabolites M1, M2, M3, M4, and M5 formed after incubation of evogliptin with human hepatocytes.

On the basis of these results, the possible in vitro metabolic pathways of evogliptin in human liver preparations are shown in Scheme 1: evogliptin is metabolized to 4-oxoevogliptin (M1), 4(S)-hydroxyevogliptin (M2), 4(R)-hydroxyevogliptin (M3), 4(S)-hydroxyevogliptin glucuronide (M4), and evogliptin $N$-sulfate (M5). 


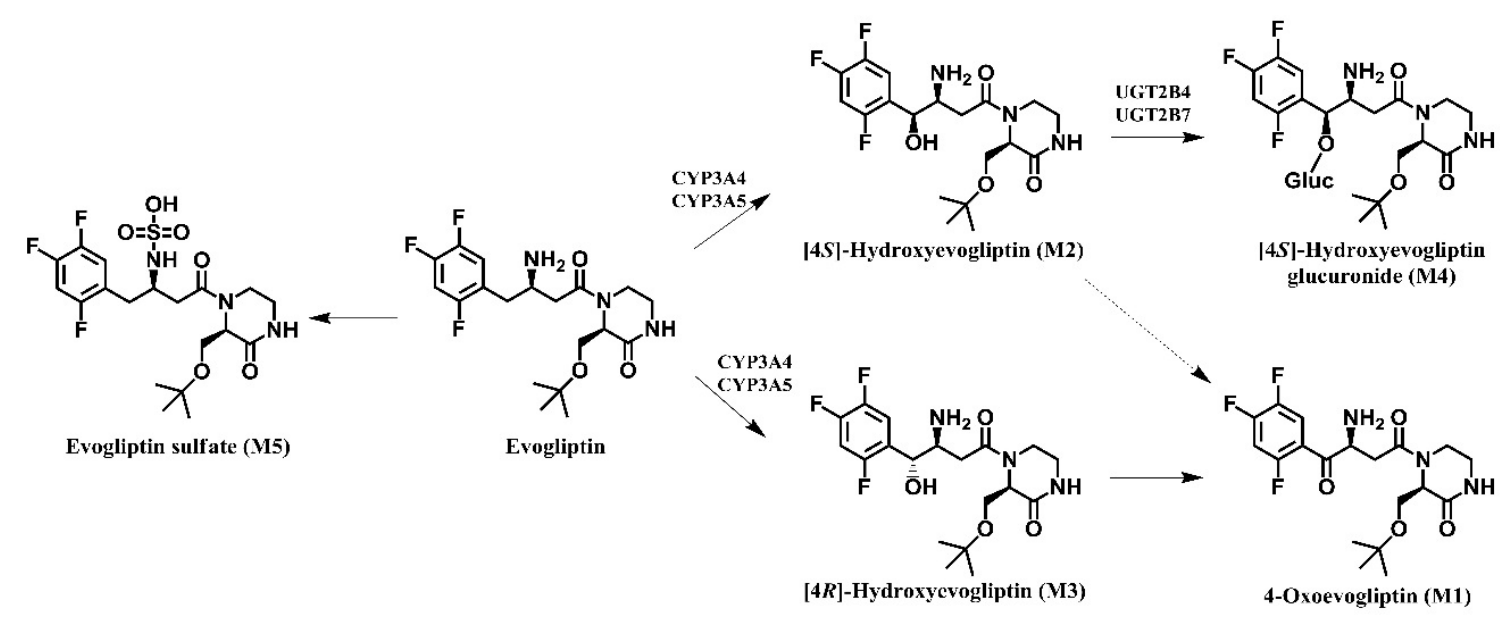

Scheme 1. Possible metabolic pathways of evogliptin in human hepatocytes, liver microsomes and liver S9 fractions.

2.2. Characterization of Human CYP Enzymes Responsible for the Formation of 4(S)-Hydroxyevogliptin (M2) and 4(R)-Hydroxyevogliptin (M3) from Evogliptin

Screening for the metabolism of evogliptin at 5 and $50 \mu \mathrm{M}$ to $4(S)$-hydroxyevogliptin (M2) and 4(R)-hydroxyevogliptin (M3) using major human cDNA-expressed CYPs 1A1, 1A2, 2A6, 2B6, 2C8, 2C9, 2C19, 2D6, 2E1, 2J2, 3A4, and 3A5 isoforms showed that CYP3A4 played a major role in the formation of 4(S)-hydroxyevogliptin (M2) and 4(R)-hydroxyevogliptin (M3), with a minor contribution by CYP3A5 (Table 2).

Table 2. Formation rates of 4(S)-hydroxyevogliptin (M2) and 4(R)-hydroxyevogliptin (M3) from 5 and $50 \mu \mathrm{M}$ evogliptin in human cDNA-expressed CYPs $(n=3$, mean \pm SD).

\begin{tabular}{|c|c|c|c|c|}
\hline \multirow{2}{*}{$\begin{array}{l}\text { Human } \\
\text { CYPs }\end{array}$} & \multicolumn{2}{|c|}{$\begin{array}{c}\text { 4(S)-Hydroxyevogliptin (M2) } \\
\text { (pmol/pmol CYP/min) }\end{array}$} & \multicolumn{2}{|c|}{$\begin{array}{c}\text { 4(R)-Hydroxyevogliptin (M3) } \\
(\mathrm{pmol} / \mathrm{pmol} \mathrm{CYP} / \mathrm{min})\end{array}$} \\
\hline & $5 \mu \mathrm{M}$ & $50 \mu \mathrm{M}$ & $5 \mu \mathrm{M}$ & $50 \mu \mathrm{M}$ \\
\hline CYP1A1 & N.D. & N.D. & N.D. & N.D. \\
\hline CYP1A2 & N.D. & N.D. & N.D. & N.D. \\
\hline CYP2A6 & N.D. & N.D. & N.D. & N.D. \\
\hline CYP2B6 & N.D. & N.D. & N.D. & N.D. \\
\hline СYP2C8 & N.D. & N.D. & N.D. & N.D. \\
\hline CYP2C9 & N.D. & N.D. & N.D. & N.D. \\
\hline CYP2C19 & N.D. & N.D. & N.D. & N.D. \\
\hline CYP2D6 & N.D. & N.D. & N.D. & N.D. \\
\hline CYP2E1 & N.D. & N.D. & N.D. & N.D. \\
\hline CYP2J2 & N.D. & N.D. & N.D. & N.D. \\
\hline CYP3A4 & $0.21 \pm 0.002$ & $0.63 \pm 0.119$ & $0.16 \pm 0.005$ & $0.57 \pm 0.113$ \\
\hline CYP3A5 & N.D. & $0.02 \pm 0.002$ & $0.01 \pm 0.000$ & $0.04 \pm 0.003$ \\
\hline
\end{tabular}

The enzyme kinetic profiles for the formation of major metabolites, 4(S)-hydroxyevogliptin (M2) and 4(R)-hydroxyevogliptin (M3) from evogliptin in pooled human liver microsomes followed single-enzyme kinetics (Figure $3 \mathrm{~A}$ ). The $K_{\mathrm{m}}, V_{\max }$, and $C l_{\text {int }}$ values of $4(S)$-hydroxyevogliptin (M2) formation were $93.4 \mu \mathrm{M}, 91.9 \mathrm{pmol} / \mathrm{mg}$ protein $/ \mathrm{min}$, and $1.0 \mu \mathrm{L} / \mathrm{min} / \mathrm{mg}$ protein, respectively, and those of $4(R)$-hydroxyevogliptin (M3) formation were $124.4 \mu \mathrm{M}, 113.0 \mathrm{pmol} / \mathrm{mg}$ protein/min, and $0.9 \mu \mathrm{L} \cdot \mathrm{min} / \mathrm{mg}$ protein, respectively (Table 3 ). 

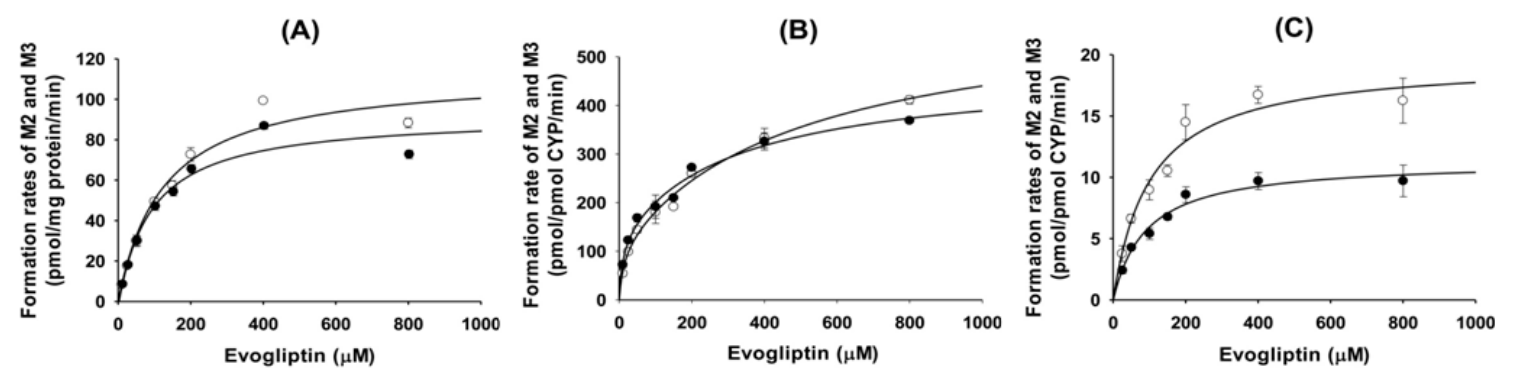

Figure 3. Enzyme kinetics for the formation of 4(S)-hydroxyevogliptin (M2, - ) and 4(R)-hydroxyevogliptin $(\mathrm{M} 3, \mathrm{O})$ from evogliptin in (A) human liver microsomes; (B) human cDNA-expressed CYP3A4; and (C) by human cDNA-expressed CYP3A5.

Table 3. Enzyme kinetic parameters for the metabolism of evogliptin to 4(S)-hydroxyevogliptin (M2) and 4(R)-hydroxyevogliptin (M3) in human liver microsomes and human cDNA-expressed CYP enzymes.

\begin{tabular}{|c|c|c|c|c|c|c|}
\hline Human CYPs & $K_{\mathrm{m}}(\mu \mathrm{M})$ & $V_{\max }$ & $C l_{\text {int }}$ & $K_{\mathrm{m} 2}(\mu \mathrm{M})$ & $V_{\max 2}$ & $\mathrm{Cl}_{\text {int2 }}$ \\
\hline \multicolumn{7}{|c|}{ Formation of 4(S)-hydroxyevogliptin (M2) } \\
\hline CYP3A4 & 10.9 & 128.8 & 11.8 & 330.1 & 340.7 & 1.0 \\
\hline CYP3A5 & 91.3 & 11.3 & 0.1 & - & - & - \\
\hline Liver microsomes & 93.4 & 91.9 & 1.0 & - & - & - \\
\hline \multicolumn{7}{|c|}{ Formation of 4(R)-hydroxyevogliptin (M3) } \\
\hline CYP3A4 & 13.0 & 112.8 & 8.7 & 511.6 & 497 & 1.0 \\
\hline CYP3A5 & 101.6 & 19.5 & 0.2 & - & - & - \\
\hline Liver microsomes & 124.4 & 113.0 & 0.9 & - & - & - \\
\hline
\end{tabular}

$V_{\max }: \mathrm{pmol} / \mathrm{min} / \mathrm{pmol} \mathrm{CYP}$ for CYP3A4 and CYP3A5, $\mathrm{pmol} / \mathrm{min} / \mathrm{mg}$ protein for liver microsomes; Clint: $\mu \mathrm{L} / \mathrm{min} / \mathrm{pmol}$ CYP for CYP3A4 and CYP3A5, $\mu \mathrm{L} / \mathrm{min} / \mathrm{mg}$ protein for liver microsomes.

The formation of 4(S)-hydroxyevogliptin (M2) and 4(R)-hydroxyevogliptin (M3) from evogliptin followed the isoenzyme equation in human cDNA-expressed CYP3A4 enzyme (Figure 3B), but showed single-enzyme kinetics in human cDNA-expressed CYP3A5 enzyme (Figure 3C). The enzyme kinetic parameters for the formation of 4(S)-hydroxyevogliptin (M2) and 4(R)-hydroxyevogliptin (M3) from evogliptin by the CYP3A4 and CYP3A5 enzymes indicate that CYP3A4 plays a prominent role in the formation of 4(S)-hydroxyevogliptin (M2) and 4(R)-hydroxyevogliptin (M3), with a minor contribution by CYP3A5 (Table 3).

The rates of formation of 4(S)-hydroxyevogliptin (M2) from 10 or $50 \mu \mathrm{M}$ evogliptin in 10 different human liver microsomes were $1.8-15.0 \mathrm{pmol} / \mathrm{mg}$ protein $/ \mathrm{min}$ and $5.2-46.4 \mathrm{pmol} / \mathrm{mg}$ protein $/ \mathrm{min}$, respectively (Figure 4A). The formation rates of 4(R)-hydroxyevogliptin (M3) from 10 or $50 \mu \mathrm{M}$ evogliptin in 10 different human liver microsomes were $1.9-14.2 \mathrm{pmol} / \mathrm{mg}$ protein $/ \mathrm{min}$ and $5.4-46.2$ $\mathrm{pmol} / \mathrm{mg}$ protein/min, respectively (Figure 4B). According to the correlation analysis using Pearson's product-moment correlation coefficient, the formation rates of 4(S)-hydroxyevogliptin (M2) and 4(R)-hydroxyevogliptin (M3) in 10 different human liver microsomes were significantly correlated $\left(r^{2} \geq 0.882, p<0.05\right)$ with testosterone $6 \beta$-hydroxylase activity, a marker enzyme of CYP3A4 (Figure 4A,B).

To further characterize the CYP enzymes responsible for the formation of 4(S)-hydroxyevogliptin (M2) and 4(R)-hydroxyevogliptin (M3) from evogliptin, an immunoinhibition study was performed by pretreating pooled human liver microsomes with an anti-CYP3A4 antibody (Figure 5). The formation of 4(S)-hydroxyevogliptin (M2) and 4(R)-hydroxyevogliptin (M3) from evogliptin in pooled human liver microsomes was potently inhibited to a maximum of $90 \%$ by the CYP3A4 antibody, suggesting that CYP3A4 played the major role in the metabolism of evogliptin to 4(S)-hydroxyevogliptin (M2) and $4(R)$-hydroxyevogliptin (M3) in human liver microsomes. 
(A)

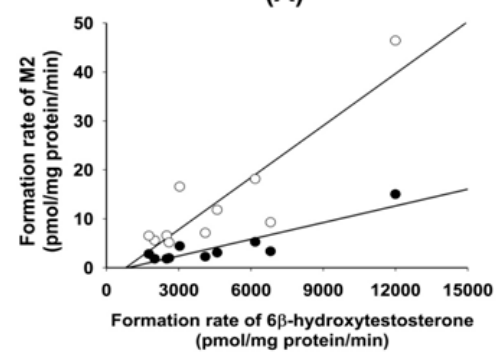

(B)

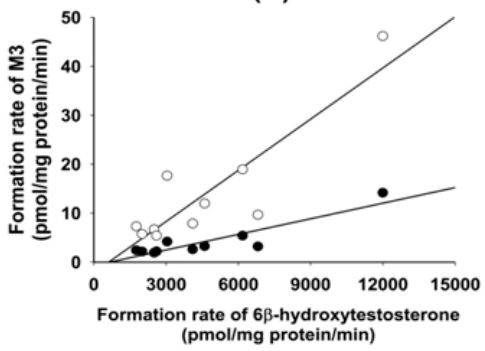

(C)

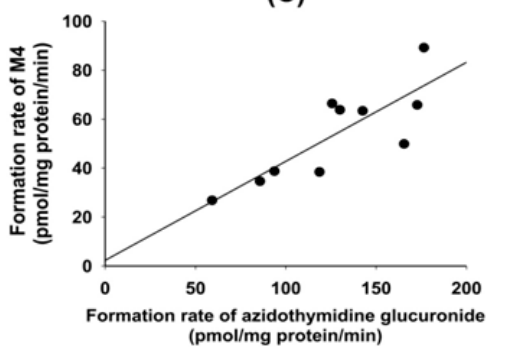

Figure 4. Correlation between the formation rates of (A) 4(S)-hydroxyevogliptin (M2) and (B) 4(R)-hydroxyevogliptin (M3) from $10 \mu \mathrm{M}(\bullet)$ and $50 \mu \mathrm{M}(\bigcirc)$ evogliptin and testosterone $6 \beta$-hydroxylase activity in 10 different human liver microsomes; (C) Correlation of the formation rates of 4(S)-hydroxyevogliptin glucuronide (M4) from $100 \mu \mathrm{M} 4(S)$-hydroxyevogliptin to azidothymidine glucuronidation activity in 10 different human liver microsomes.

(A)

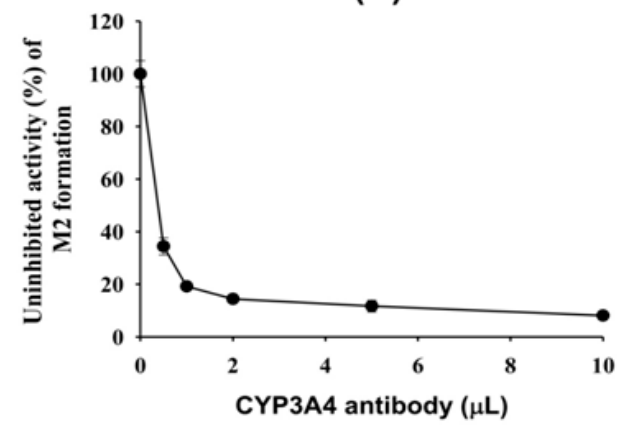

(B)

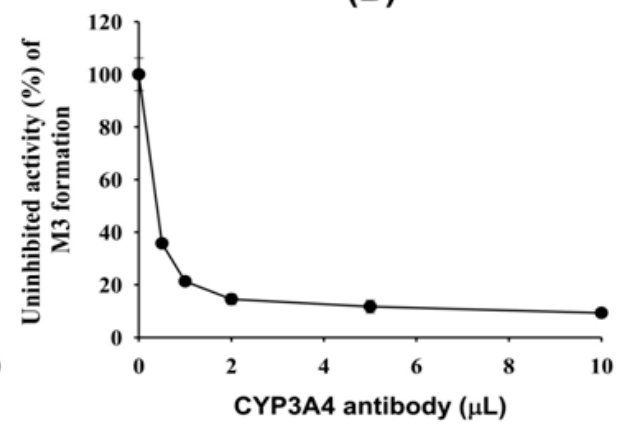

Figure 5. Effect of an anti-CYP3A4 antibody on the metabolism of evogliptin (50 $\mu \mathrm{M})$ to (A) $4(S)$ hydroxyevogliptin (M2) and (B) 4(R)-hydroxyevogliptin (M3) in pooled human liver microsomes.

\subsection{Characterization of Human UGT Enzymes Responsible for the Formation of 4-Hydroxyevogliptin Glucuronide (M4) from 4(S)-Hydroxyevogliptin}

The rates of formation of 4(S)-hydroxyevogliptin glucuronide (M4) from 4(S)-hydroxyevogliptin in pooled human liver microsomes showed a good fit to the Hill equations (Figure 6). The $K_{\mathrm{m}}, V_{\max }$ and $\mathrm{Cl}_{\text {int }}$ values for the formation of $4(S)$-hydroxyevogliptin glucuronide (M4) were $927.9 \mu \mathrm{M}, 711.4$ $\mathrm{pmol} / \mathrm{mg}$ protein $/ \mathrm{min}$, and $0.77 \mu \mathrm{L} / \mathrm{min} / \mathrm{mg}$ protein, respectively.

(A)

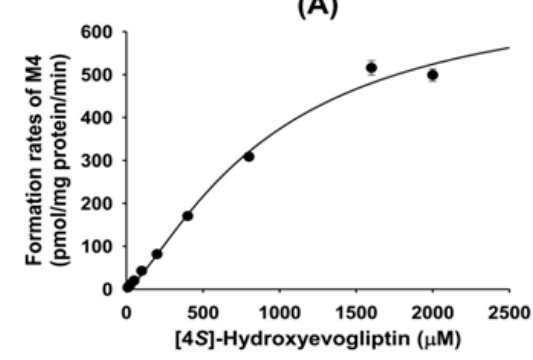

(B)

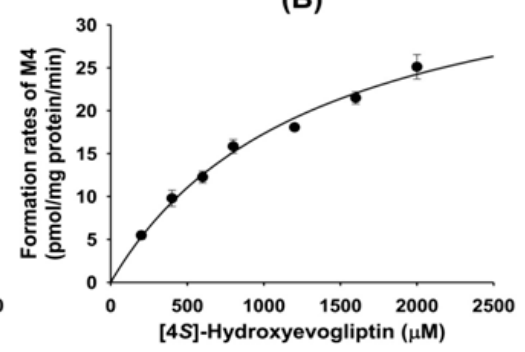

(C)

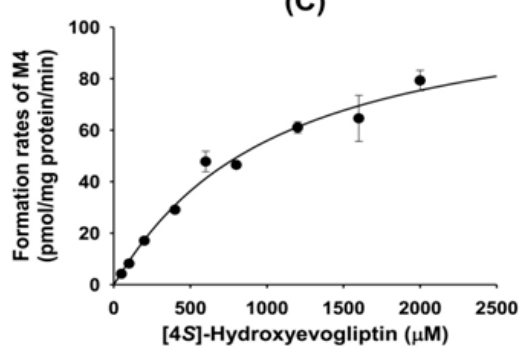

Figure 6. Enzyme kinetics for the metabolism of 4(S)-hydroxyevogliptin (M2) to 4(S)-hydroxyevogliptin glucuronide (M4) in (A) pooled human liver microsomes; (B) human cDNA-expressed UGT2B4; and (C) human cDNA-expressed UGT2B7.

Screening using human cDNA-expressed UGT 1A1, 1A3, 1A4, 1A6, 1A7, 1A8, 1A9, 1A10, 2B4, 2B7, 2B15 and 2B17 isoforms for the glucuronidation of 4(S)-hydroxyevogliptin (M2) to 4(S)-hydroxyevogliptin glucuronide (M4) showed that the UGT2B4 and UGT2B7 enzymes played major roles in the formation of M4, and that the UGT 1A1, 1A3, 1A4, 1A6, 1A7, 1A8, 1A9, 1A10, 2B15, and 2B17 enzymes did not contribute (Table 4). 
Table 4. Formation rates of 4(S)-hydroxyevogliptin glucuronide (M4) from 50 and $300 \mu \mathrm{M}$ 4(S)-hydroxyevogliptin (M2) in human cDNA-expressed UGTs (mean $\pm \mathrm{SD}, n=3$ ).

\begin{tabular}{ccc}
\hline \multirow{2}{*}{ Human UGTs } & $\begin{array}{c}\text { 4(S)-Hydroxyevogliptin Glucuronide (M4) } \\
\text { (pmol/mg protein/min) }\end{array}$ \\
\cline { 2 - 3 } & $\mathbf{5 0} \boldsymbol{\mu M}$ & $\mathbf{3 0 0} \boldsymbol{\mu M}$ \\
\hline UGT1A1 & N.D. & N.D. \\
UGT1A3 & N.D. & N.D. \\
UGT1A4 & N.D. & N.D. \\
UGT1A6 & N.D. & N.D. \\
UGT1A7 & N.D. & N.D. \\
UGT1A8 & N.D. & N.D. \\
UGT1A9 & N.D. & N.D. \\
UGT1A10 & N.D. & N.D. \\
UGT2B4 & N.D. & $6.22 \pm 0.31$ \\
UGT2B7 & $7.46 \pm 0.77$ & $32.99 \pm 1.04$ \\
UGT2B15 & N.D. & N.D. \\
UGT2B17 & N.D. & N.D. \\
\hline
\end{tabular}

N.D., not detected (<5 $\mathrm{pmol} / \mathrm{mg}$ protein $/ \mathrm{min})$.

The rates of formation of 4(S)-hydroxyevogliptin glucuronide (M4) from 4(S)-hydroxyevogliptin (M2) followed single-enzyme kinetics with UGT2B4 and Hill equation kinetics with UGT2B7 (Figure 6). The $K_{\mathrm{m}}, V_{\max }$, and $C l_{\text {int }}$ values for the formation of 4(S)-hydroxyevogliptin glucuronide (M4) formation were $1,328 \mu \mathrm{M}, 40.3 \mathrm{pmol} / \mathrm{mg}$ protein $/ \mathrm{min}$, and $0.03 \mu \mathrm{L} / \mathrm{min} / \mathrm{mg}$ protein, respectively, for UGT2B4; and $1003.8 \mu \mathrm{M}, 112 \mathrm{pmol} / \mathrm{mg}$ protein $/ \mathrm{min}$, and $0.1 \mu \mathrm{L} / \mathrm{min} / \mathrm{mg}$ protein, respectively, for UGT2B7.

The rates of formation of 4(S)-hydroxyevogliptin glucuronide (M4) from $100 \mu \mathrm{M} 4(S)$ hydroxyevogliptin (M2) in 10 different human liver microsomes were $26.8-89.2 \mathrm{pmol} / \mathrm{mg}$ protein $/ \mathrm{min}$ (Figure 4C). The correlation analysis demonstrated that the formation rates of 4(S)-hydroxyevogliptin glucuronide (M4) in 10 different human liver microsomes were significantly correlated $\left(r^{2}=0.834\right.$, $p<0.05$ ) with UGT2B7-catalzyed azidothymidine $\mathrm{N}$-glucuronidation (Figure 4C).

\section{Discussion}

In vitro metabolism of evogliptin using human hepatocytes, liver microsomes, and liver S9 fractions was investigated for the first time. Evogliptin and five of its metabolites, M1-M5, were characterized by LC-HRMS analysis following incubation with human hepatocytes (Figure 1A). Incubation of evogliptin with human liver S9 fractions in the presence of NADPH and PAPS resulted in the formation of 4(S)-hydroxyevogliptin (M2), 4(R)-hydroxyevogliptin (M3), and evogliptin N-sulfate (M5), as determined by LC-HRMS analysis (Figure 1B). Incubation of 4(S)-hydroxyevogliptin (M2) with pooled human liver microsomes in the presence of NADPH and UDPGA resulted in the formation of 4(S)-hydroxyevogliptin glucuronide (M4) and 4-oxoevogliptin (M1) (Figure 1C). Incubation of 4(R)-hydroxyevogliptin (M3) with pooled human liver microsomes in the presence of NADPH and UDPGA resulted in the formation of 4-oxoevogliptin (M1) (Figure 1D). Five metabolites were identified on the basis of the retention time and product ions by comparison with the corresponding authentic standards (Table 1, Figure 2). Evogliptin was metabolized to the following five metabolites in human liver: 4(S)-hydroxyevogliptin (M2) and 4(R)-hydroxyevogliptin (M3) via hydroxylation, evogliptin $\mathrm{N}$-sulfate (M5) via sulfation, 4-oxoevogliptin (M1) from 4(S)-hydroxyevogliptin (M2) and 4(R)-hydroxyevogliptin (M3) via dehydrogenation, and 4(S)-hydroxyevogliptin glucuronide (M4) from 4(S)-hydroxyevogliptin (M2) via glucuronidation (Figure 3). Enzyme kinetic parameters for the formation of 4(S)-hydroxyevogliptin (M2) and 4(R)-hydroxyevogliptin (M3) from evogliptin in pooled human liver microsomes indicated that these compounds were the major metabolites. 
To identify the CYP enzymes responsible for the formation of 4(S)-hydroxyevogliptin (M2) and 4(R)-hydroxyevogliptin (M3) from evogliptin, we performed a correlation analysis and immunoinhibition assay using human liver microsomes and performed a screening and evaluated enzyme kinetics using human cDNA-expressed CYP enzymes. Screening using cDNA-expressed human CYP enzymes showed that CYP3A4 played the predominant role in the formation of 4(S)-hydroxyevogliptin (M2) and $4(R)$-hydroxyevogliptin (M3), with a minor contribution by CYP3A5 (Table 2). The formation rates of 4(S)-hydroxyevogliptin (M2) and 4(R)-hydroxyevogliptin (M3) from evogliptin in 10 different human liver microsomes were significantly correlated with CYP3A4-mediated testosterone $6 \beta$-hydroxylase activity $\left(r^{2} \geq 0.882, p<0.05\right.$, Figure $\left.4 \mathrm{~A}, \mathrm{~B}\right)$. An anti-CYP3A4 antibody potently inhibited the formation of 4(S)-hydroxyevogliptin (M2) and 4(R)-hydroxyevogliptin (M3) by up to $90 \%$ (Figure 5) in pooled human liver microsomes. Therefore, the CYP3A4 enzyme played a major role in the hydroxylation of evogliptin to 4(S)-hydroxyevogliptin (M2) and 4(R)-hydroxyevogliptin (M3), with a minor contribution by CYP3A5, in human liver microsomes.

Metabolism of 4(S)-hydroxyevogliptin (M2) to 4(S)-hydroxyevogliptin glucuronide (M4) was mediated by human cDNA-expressed UGT2B4 and UGT2B7 (Table 4). These results were supported by a correlation analysis of the rates of formation of 4(S)-hydroxyevogliptin glucuronide (M4) in 10 different human liver microsomes and UGT2B7-catalzyed azidothymidine glucuronidase activity, which showed a significant correlation $\left(r^{2}=0.834, p<0.05\right)$ (Figure $4 \mathrm{C}$ ).

Formation of 4(S)-hydroxyevogliptin (M2) and 4(R)-hydroxyevogliptin (M3) from evogliptin was the major metabolic pathway catalyzed by CYP3A4/5.4(S)-Hydroxyevogliptin (M2) was further metabolized to 4(S)-hydroxyevogliptin glucuronide (M4) by UGT2B4 and UGT2B7. 4(S)-hydroxyevogliptin (M2) and 4(R)-hydroxyevogliptin (M3) were further metabolized to 4-oxoevogliptin (M1). The CYP3A4 enzyme, which is responsible for the hydroxylation of evogliptin, is the most abundant CYP enzyme in the human small intestine and liver [12,16-18]. CYP3A plays a key role in the metabolism of $\sim 30 \%$ of all drugs [12], and its activity shows wide interindividual variation due to genetic polymorphisms [16-18]. Genetic polymorphisms have also been described for UGT2B4 and UGT2B7, which were responsible for the glucuronidation of 4(S)-hydroxyevogliptin (M2) to M4 $[19,20]$. Therefore, the interindividual differences in the metabolism of evogliptin in humans is likely due to genetic variants of the CYP3A4, UGT2B4, and UGT2B7 enzymes responsible for the metabolism of evogliptin.

\section{Experimental Section}

\subsection{Materials}

Evogliptin, 4-oxoevogliptin, 4(S)-hydroxyevogliptin, 4(R)-hydroxyevogliptin, 4(S)-hydroxyevogliptin glucuronide, and evogliptin $N$-sulfate were provided by Dong-A ST Co. (Yongin, Korea). William's E medium, potassium phosphate monobasic, potassium phosphate dibasic trihydrate, reduced $\beta$-nicotinamide adenine dinucleotide phosphate tetrasodium salt (NADPH), Trizma ${ }^{\circledR}$ Base, Trizma $^{\circledR} \mathrm{HCl}$, uridine-5-diphosphoglucuronic acid trisodium salt (UDPGA), alamethicin (from Trichoderma viride), 3'-phosphoadenosine-5'-phosphosulfate (PAPS), formic acid, and 1-methyl-4phenylpyridinium iodide (MPPI, used as an internal standard) were purchased from Sigma-Aldrich Co. (St. Louis, MO, USA). Acetonitrile and water (LC-MS grade) were obtained from Fisher Scientific (Fairlawn, NJ, USA). The other reagents were of the highest quality available.

Cryopreserved human hepatocytes (catalog no. 454504), cryohepatocyte purification kit (catalog no. 454534), pooled and individual human liver microsomes (coded HG3, HH18, HK23, HG32, HK37, HG43, HH47, HG56, HG64, and HG74), human cDNA-expressed CYP enzymes (CYPs 1A1, 1A2, 2A6, 2B6, 2C8, 2C9, 2C19, 2D6, 2E1, 2J2, 3A4, and 3A5), human cDNA-expressed UGT enzymes (UGTs 1A1, 1A3, 1A4, 1A6, 1A7, 1A8, 1A9, 1A10, 2B4, 2B7, 2B15, and 2B17), and human-specific antibody for the immunoinhibition of human CYP3A4 (anti-CYP3A4) were purchased from Corning Life Sciences (Woburn, MA, USA). 


\subsection{Identification of the Metabolites of Evogliptin in Human Hepatocytes}

Cryopreserved human hepatocytes were purified and recovered using a cryohepatocyte purification kit (Woburn) according to the manufacturer's protocol. Purified human hepatocytes were resuspended in William's E medium to a final density of $1.28 \times 10^{6}$ cells $/ \mathrm{mL}$, and then $62.5 \mu \mathrm{L}$ of human hepatocyte suspensions $\left(8 \times 10^{4}\right.$ cells $)$ and $62.5 \mu \mathrm{L}$ of $100 \mu \mathrm{M}$ evogliptin in William's $\mathrm{E}$ medium were added to a 96-well plate and incubated for $4 \mathrm{~h}$ at $37^{\circ} \mathrm{C}$ in a $\mathrm{CO}_{2}$ incubator. The reaction was terminated by the addition of $125 \mu \mathrm{L}$ of ice-cold acetonitrile to each sample well, followed by centrifugation at $13,000 \mathrm{rpm}$ for $4 \mathrm{~min}$ at $4{ }^{\circ} \mathrm{C}$. Then, $40 \mu \mathrm{L}$ of the supernatant were diluted with $60 \mu \mathrm{L}$ of deionized water and an aliquot $(5 \mu \mathrm{L})$ was injected onto LC-HRMS system to identify metabolites of evogliptin.

\subsection{Identification of Metabolites of Evogliptin in Human Liver S9 Fractions}

The incubation mixture consisted of $50 \mathrm{mM}$ potassium phosphate buffer ( $\mathrm{pH} 7.4), 10 \mathrm{mM}$ magnesium chloride, pooled human liver $\mathrm{S} 9$ fractions (150 $\mu \mathrm{g}$ protein), $1 \mathrm{mM} \mathrm{NADPH,} 2 \mathrm{mM}$ UDPGA, $0.2 \mathrm{mM}$ PAPS and $10 \mu \mathrm{M}$ evogliptin in a total volume of $300 \mu \mathrm{L}$. The incubation mixture was incubated for $60 \mathrm{~min}$ at $37^{\circ} \mathrm{C}$ in a shaking water bath. The incubation was stopped by the addition of $300 \mu \mathrm{L}$ of ice-cold acetonitrile, followed by centrifugation at $13,000 \mathrm{rpm}$ for $4 \mathrm{~min}$ at $4{ }^{\circ} \mathrm{C}$. The supernatant was evaporated using a vacuum concentrator and the residue was dissolved in $100 \mu \mathrm{L}$ of $15 \%$ acetonitrile. An aliquot $(5 \mu \mathrm{L})$ was injected onto the LC-HRMS system.

\subsection{Identification of Metabolites of Evogliptin in Human Liver Microsomes}

The incubation mixture consisted of $50 \mathrm{mM}$ potassium phosphate buffer ( $\mathrm{pH} 7.4), 10 \mathrm{mM}$ magnesium chloride, pooled human liver microsomes ( $60 \mu \mathrm{g}$ protein), $1 \mathrm{mM}$ NADPH, $2 \mathrm{mM}$ UDPGA, and $10 \mu \mathrm{M}$ evogliptin in a total volume of $300 \mu \mathrm{L}$. The reaction mixture was incubated for $60 \mathrm{~min}$ at $37^{\circ} \mathrm{C}$ in a shaking water bath. The incubation was stopped by the addition of $300 \mu \mathrm{L}$ of ice-cold acetonitrile, followed by centrifugation at $13,000 \mathrm{rpm}$ for $4 \mathrm{~min}$ at $4{ }^{\circ} \mathrm{C}$, and the supernatant was evaporated. The residue was reconstituted in $100 \mu \mathrm{L}$ of $15 \%$ acetonitrile, and an aliquot $(5 \mu \mathrm{L})$ was analyzed by LC-HRMS.

\subsection{Enzyme Kinetics of Evogliptin Metabolism to [4S]-hydroxyevogliptin (M2) and [4R]-hydroxyevogliptin} (M3) in Human Liver Microsomes

Preliminary experiments demonstrated that the metabolism of evogliptin to 4(S)-hydroxyevogliptin (M2) and 4(R)-hydroxyevogliptin (M3) proceeded linearly with incubation time (10-30 min) and liver microsomal protein concentration $(0.1-0.3 \mathrm{mg} / \mathrm{mL})$. Thus, a $20 \mathrm{~min}$ incubation time and $0.15 \mathrm{mg} / \mathrm{mL}$ microsomal protein concentration were used in subsequent experiments.

The reaction mixture comprised $50 \mathrm{mM}$ potassium phosphate buffer ( $\mathrm{pH}$ 7.4), $10 \mathrm{mM}$ magnesium chloride, pooled human liver microsomes (15 $\mu \mathrm{g}$ protein), and various concentrations of evogliptin (10 to $800 \mu \mathrm{M}$; final acetonitrile concentration not exceeding $0.5 \%, v / v$ ) was preincubated for $3 \mathrm{~min}$ at $37^{\circ} \mathrm{C}$. The reaction was initiated by adding NADPH, and the mixture was further incubated (final volume of $100 \mu \mathrm{L}$ ) for $20 \mathrm{~min}$ at $37^{\circ} \mathrm{C}$ in a shaking water bath. The reaction was terminated by adding $100 \mu \mathrm{L}$ of MPPI (internal standard, $50 \mathrm{ng} / \mathrm{mL}$ ) in ice-cold acetonitrile. The mixture was centrifuged at $13,000 \mathrm{rpm}$ for $4 \mathrm{~min}$ at $4{ }^{\circ} \mathrm{C}$. Subsequently, $50 \mu \mathrm{L}$ of the supernatant were diluted with $50 \mu \mathrm{L}$ of deionized water and an aliquot $(5 \mu \mathrm{L})$ was injected onto the LC-MS/MS system.

\subsection{Metabolism of Evogliptin in Human cDNA-Expressed CYP Enzymes}

The reaction mixture comprised $50 \mathrm{mM}$ potassium phosphate buffer ( $\mathrm{pH}$ 7.4), $10 \mathrm{mM}$ magnesium chloride, evogliptin (5 or $50 \mu \mathrm{M})$, and 12 human cDNA-expressed CYP enzymes (CYPs 1A1, 1A2, 2A6, 2B6, 2C8, 2C9, 2C19, 2D6, 2E1, 2J2, 3A4, and 3A5; 4 pmol) and was preincubated for $3 \mathrm{~min}$ at $37^{\circ} \mathrm{C}$. The reaction was initiated by addition of NADPH, and the mixture was further incubated (final volume of $100 \mu \mathrm{L}$ ) for $20 \mathrm{~min}$ at $37^{\circ} \mathrm{C}$ in a shaking water bath. The reaction was terminated by adding 
$100 \mu \mathrm{L}$ of MPPI (internal standard, $50 \mathrm{ng} / \mathrm{mL}$ ) in ice-cold acetonitrile. The mixture was centrifuged at 13,000 rpm for $4 \mathrm{~min}$ at $4{ }^{\circ} \mathrm{C}$. Continuously, $50 \mu \mathrm{L}$ of the supernatant were diluted with $50 \mu \mathrm{L}$ of deionized water and an aliquot $(5 \mu \mathrm{L})$ was analyzed using the LC-MS/MS system.

For the enzyme kinetic experiments, various concentrations of evogliptin (10 to $800 \mu \mathrm{M}$; final acetonitrile concentration not exceeding $0.5 \%, v / v$ ) were incubated with human cDNA-expressed CYP enzymes (CYPs 3A4 and 3A5; 4 pmol), $1 \mathrm{mM} \mathrm{NADPH}$, and $10 \mathrm{mM} \mathrm{MgCl}_{2}$ in $50 \mathrm{mM}$ potassium phosphate buffer ( $\mathrm{pH} \mathrm{7.4)}$ for $20 \mathrm{~min}$ at $37^{\circ} \mathrm{C}$ in a shaking water bath. After addition of ice-cold acetonitrile containing internal standard (MPPI, $50 \mathrm{ng} / \mathrm{mL}$ ), the mixture was centrifuged and diluted as described above, and an aliquot $(5 \mu \mathrm{L})$ was injected onto the LC-MS/MS system.

\subsection{Correlation Analysis of Evogliptin Metabolism with Probe Substrate Activities in Human Liver Microsomes}

Evogliptin $(10$ and $50 \mu \mathrm{M})$ was incubated with 10 different human liver microsomes (15 $\mu \mathrm{g}$ protein), $1 \mathrm{mM} \mathrm{NADPH}$, and $10 \mathrm{mM}$ magnesium chloride in $50 \mathrm{mM}$ potassium phosphate buffer (pH 7.4) for $20 \mathrm{~min}$ at $37^{\circ} \mathrm{C}$ in a shaking water bath. The correlation coefficients between the formation rates of 4(S)-hydroxyevogliptin (M2) or 4(R)-hydroxyevogliptin (M3) from evogliptin and specific CYP activities in human liver microsomes provided by Corning Life Sciences were evaluated by the Pearson product-moment correlation coefficient using Sigma Stat software (ver. 2.0; Systat Software Inc., San Jose, CA, USA). A $p$ value $<0.05$ was considered to indicate significance.

\subsection{Immunoinhibition of Evogliptin Metabolism with an Anti-CYP3A4 Antibody}

Immunoinhibition experiments were conducted by incubating pooled human liver microsomes with various amounts of an anti-CYP3A4 antibody for $15 \mathrm{~min}$ on ice, and then the reaction was initiated by the addition of $50 \mathrm{mM}$ potassium phosphate buffer ( $\mathrm{pH} 7.4), 50 \mu \mathrm{M}$ evogliptin, $10 \mathrm{mM}$ magnesium chloride, and $1 \mathrm{mM}$ NADPH. Control incubations were performed using liver microsomes and $25 \mathrm{mM}$ Tris buffer but without the anti-CYP3A4 antibody, which was prepared in this buffer.

\subsection{Metabolism of 4(S)-Hydroxyevogliptin (M2) and 4(R)-Hydroxyevogliptin (M3) to 4-Oxoevogliptin (M1) and 4(S)-hydroxyevogliptin Glucuronide (M4) in Human Liver Microsomes}

The incubation mixture consisted of $50 \mathrm{mM}$ potassium phosphate buffer ( $\mathrm{pH} 7.4), 10 \mathrm{mM}$ magnesium chloride, pooled human liver microsomes (60 $\mu$ g protein), $1 \mathrm{mM} \mathrm{NADPH}, 2 \mathrm{mM}$ UDPGA, and $10 \mu \mathrm{M} 4(S)$-hydroxyevogliptin (M2) or 4(R)-hydroxyevogliptin (M3) in a total volume of $300 \mu \mathrm{L}$. The incubation mixture was incubated for $60 \mathrm{~min}$ at $37^{\circ} \mathrm{C}$ in a shaking water bath. The incubation was stopped by the addition of $300 \mu \mathrm{L}$ of ice-cold acetonitrile followed by centrifugation at 13,000 rpm for $4 \mathrm{~min}$ at $4{ }^{\circ} \mathrm{C}$. Subsequently, the supernatant was evaporated and the residue was reconstituted in $100 \mu \mathrm{L}$ of $15 \%$ acetonitrile. An aliquot $(5 \mu \mathrm{L})$ was injected onto the LC-HRMS system.

\subsection{Metabolism of 4(S)-Hydroxyevogliptin to 4(S)-Hydroxyevogliptin Glucuronide (M4) by Human cDNA-Expressed UGT Enzymes}

To investigate the UGT enzymes involved in the glucuronidation of 4(S)-hydroxyevogliptin (M2), the incubation mixture (final volume of $100 \mu \mathrm{L}$ ) containing $50 \mathrm{mM}$ Tris buffer (pH 7.4), $10 \mathrm{mM}$ magnesium chloride, $0.025 \mathrm{mg} / \mathrm{mL}$ alamethicin, 4(S)-hydroxyevogliptin (M2) (50 or $300 \mu \mathrm{M})$, and 12 human cDNA-expressed UGT enzymes (UGTs 1A1, 1A3, 1A4, 1A6, 1A7, 1A8, 1A9, 1A10, 2B4, 2B7, $2 \mathrm{~B} 15$, and 2B17; $10 \mu \mathrm{g}$ protein) was preincubated for $3 \mathrm{~min}$ at $37^{\circ} \mathrm{C}$. The reaction was initiated by adding UDPGA, and the mixture was further incubated (final volume of $100 \mu \mathrm{L}$ ) for $20 \mathrm{~min}$ at $37^{\circ} \mathrm{C}$ in a shaking water bath. The reaction was terminated by adding $100 \mu \mathrm{L}$ of MPPI (internal standard, $50 \mathrm{ng} / \mathrm{mL}$ ) in ice-cold acetonitrile. The mixture was centrifuged at 13,000 rpm for $4 \mathrm{~min}$ at $4{ }^{\circ} \mathrm{C}, 50 \mu \mathrm{L}$ of the supernatant were diluted with $50 \mu \mathrm{L}$ of deionized water, and an aliquot $(5 \mu \mathrm{L})$ was analyzed using the LC-MS/MS system. 


\subsection{Enzyme Kinetics for the Metabolism of 4(S)-Hydroxyevogliptin to 4(S)-Hydroxyevogliptin Glucuronide} (M4) in Human Liver Microsomes and cDNA-Expressed UGT Enzymes

Preliminary experiments showed that the glucuronidation of 4(S)-hydroxyevogliptin to 4(S)-hydroxyevogliptin glucuronide (M4) was linear with incubation time over $30 \mathrm{~min}$ and human liver microsomal protein concentration $(0.1-0.3 \mathrm{mg} / \mathrm{mL})$. Therefore, a $20 \mathrm{~min}$ incubation time and $0.2 \mathrm{mg} / \mathrm{mL}$ microsomal protein concentration were selected for enzyme kinetics experiments. The reaction mixture comprised $50 \mathrm{mM}$ Tris buffer ( $\mathrm{pH} 7.4$ ), $10 \mathrm{mM}$ magnesium chloride, $0.025 \mathrm{mg} / \mathrm{mL}$ alamethicin, pooled human liver microsomes $(20 \mu \mathrm{g}$ protein), and various concentrations of 4(S)-hydroxyevogliptin (M2) (10 to 2,000 $\mu \mathrm{M}$; final acetonitrile concentration not exceeding $0.5 \%, v / v)$, and was preincubated for $3 \mathrm{~min}$ at $37^{\circ} \mathrm{C}$. The reaction was initiated by adding UDPGA, and the mixture was further incubated (final volume of $100 \mu \mathrm{L}$ ) for $20 \mathrm{~min}$ at $37^{\circ} \mathrm{C}$ in a shaking water bath. The reaction was stopped by adding $100 \mu \mathrm{L}$ of MPPI (internal standard, $50 \mathrm{ng} / \mathrm{mL}$ ) in ice-cold acetonitrile. The mixture was centrifuged at 13,000 rpm for $4 \mathrm{~min}$ at $4{ }^{\circ} \mathrm{C}$. Next, $50 \mu \mathrm{L}$ of the supernatant were diluted with $50 \mu \mathrm{L}$ of deionized water and an aliquot $(5 \mu \mathrm{L})$ was injected onto the LC-MS/MS system.

For the enzyme kinetic study, various concentrations of 4(S)-hydroxyevogliptin (M2) (25 to $2000 \mu \mathrm{M}$; final acetonitrile concentration not exceeding $0.5 \%, v / v$ ) were incubated with human cDNA-expressed UGT2B4 or UGT2B7 enzymes ( $20 \mu \mathrm{g}$ protein), $2 \mathrm{mM}$ UDPGA, $0.025 \mathrm{mg} / \mathrm{mL}$ alamethicin, and $10 \mathrm{mM}$ magnesium chloride in $50 \mathrm{mM}$ Tris buffer ( $\mathrm{pH}$ 7.4) for $20 \mathrm{~min}$ at $37^{\circ} \mathrm{C}$ in a shaking water bath. After adding ice-cold acetonitrile containing internal standard (MPPI, $50 \mathrm{ng} / \mathrm{mL}$ ), the mixture was centrifuged and diluted as described above, and an aliquot $(5 \mu \mathrm{L})$ was analyzed using the LC-MS/MS system.

\subsection{Correlation Analysis of 4(S)-Hydroxyevogliptin Metabolism to 4(S)-Hydroxyevogliptin Glucuronide (M4) with Probe Substrate Activities in Human Liver Microsomes}

The formation rates of 4(S)-hydroxyevogliptin glucuronide (M4) from 4(S)-hydroxyevogliptin (M2) were evaluated by incubating $4(S)$-hydroxyevogliptin $(100 \mu \mathrm{M})$ with 10 different human liver microsomes ( $20 \mu \mathrm{g}$ protein), $2 \mathrm{mM}$ UDPGA, $0.025 \mathrm{mg} / \mathrm{mL}$ alamethicin, and $10 \mathrm{mM}$ magnesium chloride in $50 \mathrm{mM}$ Tris buffer ( $\mathrm{pH}$ 7.4) for $20 \mathrm{~min}$ at $37^{\circ} \mathrm{C}$ in a shaking water bath. The correlation coefficients between the formation rates of 4(S)-hydroxyevogliptin glucuronide (M4) and specific UGT activities in human liver microsomes reported by Corning Life Sciences were determined by the Pearson product-moment correlation coefficient using Sigma Stat Software (Systat Software Inc.). A $p$ value $<0.05$ was considered to indicate significance.

\subsection{LC-HRMS and LC-MS/MS Analysis of Evogliptin and Its Metabolites}

To identify evogliptin and its metabolites, an Exactive Orbitrap mass spectrometer (Thermo Scientific, San Jose, CA, USA) coupled to an Accela ultra-performance liquid chromatography system was used. The separation was performed on a Unison-C8 column $(3.0 \mu \mathrm{m}, 2.0 \mathrm{~mm}$ i.d. $\times 75 \mathrm{~mm}$; Imtakt Corporation, Kyoto, Japan) using a gradient elution of $5 \%$ acetonitrile in $0.1 \%$ formic acid (mobile phase A) and $95 \%$ acetonitrile in $0.1 \%$ formic acid (mobile phase B) at a flow rate of $0.3 \mathrm{~mL} / \mathrm{min}$ : $14 \%$ B for $8.5 \mathrm{~min}, 14 \%$ to $90 \%$ B for $3.0 \mathrm{~min}, 90 \%$ B for $3.0 \mathrm{~min}, 90 \%$ to $14 \%$ B for $0.1 \mathrm{~min}$, and $14 \% \mathrm{~B}$ for $5.5 \mathrm{~min}$. The column and autosampler temperatures were $40^{\circ} \mathrm{C}$ and $6{ }^{\circ} \mathrm{C}$, respectively. The electrospray ionization (ESI) in positive and negative mode was used with the following electrospray source settings: spray voltage, $4.0 \mathrm{kV}$ in positive mode and $-3.0 \mathrm{kV}$ in negative mode; vaporizer temperature, $350{ }^{\circ} \mathrm{C}$; capillary temperature, $330{ }^{\circ} \mathrm{C}$; sheath gas pressure, 35 arbitrary units; and auxiliary gas pressure, 15 arbitrary units. Higher-energy collision dissociation (HCD) with a collision energy of 10 to $40 \mathrm{eV}$ was employed to investigate the fragmentation pattern of evogliptin and its metabolites. The mass measurement accuracy for evogliptin and its metabolites did not exceed $5 \mathrm{ppm}$, representing a good correlation between the theoretical mass based on the molecular elemental composition and the experimental mass obtained from the full-scan HRMS analysis. The proposed structures for the product ions of evogliptin and its metabolites were determined using the Mass Frontier software (ver. 6.0; HighChem Ltd., Bratislava, Slovakia). 
For the quantification of evogliptin and its metabolites, a Nanospace SI-2 LC system (Shiseido, Tokyo, Japan) coupled to a tandem quadrupole mass spectrometer (TSQ Quantum Access; Thermo Fisher Scientific) was used. The ESI source settings for the ionization of evogliptin and its metabolites were as follows: spray voltage, $4.5 \mathrm{kV}$; vaporizer temperature, $350^{\circ} \mathrm{C}$; capillary temperature, $330^{\circ} \mathrm{C}$; sheath gas pressure, 35 arbitrary units; and auxiliary gas pressure, 15 arbitrary units. The collision energy for evogliptin and its five metabolites, M1-M5, were $18 \mathrm{~V}, 12 \mathrm{~V}, 13 \mathrm{~V}, 13 \mathrm{~V}, 18 \mathrm{~V}$, and $31 \mathrm{~V}$, respectively. To quantify evogliptin and its metabolites, selective reaction monitoring mode using specific precursor and product ion transitions was applied: $\mathrm{m} / \mathrm{z} 402.2 \rightarrow 346.1$ for evogliptin, $\mathrm{m} / \mathrm{z}$ $416.1 \rightarrow 360.0$ for 4-oxoevogliptin (M1), $m / z 418.0 \rightarrow 362.0$ for 4(S)- and 4(R)-hydroxyevogliptin (M2 and M3, respectively), $m / z 594.2 \rightarrow 538.1$ for $4(S)$-hydroxyevogliptin glucuronide (M4), $m / z 480.3 \rightarrow 251.8$ for evogliptin $N$-sulfate (M5), and $m / z \quad 170.1 \rightarrow 128.2$ for MPP+ iodide (internal standard). Peak areas for internal standard, evogliptin, and its metabolites were integrated using the Xcalibur ${ }^{\circledR}$ software (Thermo Fisher Scientific).

\subsection{Data Analysis}

Results represent the average of three independent experiments using human liver microsomes and human cDNA-expressed CYP and UGT enzymes. The kinetic parameters ( $K_{\mathrm{m}}$ and $\left.V_{\max }\right)$ for hydroxylation and glucuronidation were determined using the Michaelis-Menten equation $[V=$ $\left.V_{\max } \cdot \mathrm{S} /\left(K_{\mathrm{m}}+\mathrm{S}\right)\right]$, the Hill equation $\left[V=V_{\max } \cdot \mathrm{S}^{\mathrm{n}} /\left(K_{\mathrm{m}^{\mathrm{n}}}+\mathrm{S}^{\mathrm{n}}\right)\right]$, or the isoenzyme equation $\left[V=V_{\max 1} \cdot\left(\mathrm{S} / K_{\mathrm{m} 1}\right) /\right.$ $\left.\left(1+\mathrm{S} / K_{\mathrm{m} 1}\right)+V_{\max 2} \cdot\left(\mathrm{S} / K_{\mathrm{m} 2}\right) /\left(1+\mathrm{S} / K_{\mathrm{m} 2}\right)\right]$ with the Enzyme Kinetics software (version 1.3; Systat Software Inc.). In the above-mentioned equations, $V$ was the velocity of the reaction at substrate concentration [S], $V_{\max }$ was the maximum velocity, $K_{\mathrm{m}}$ was the substrate concentration at which the $V$ was half of $V_{\max }$ and $n$ is the Hill constant. The intrinsic clearance $\left(C l_{\text {int }}\right)$ was calculated as $V_{\max } / K_{\mathrm{m}}$.

\section{Conclusions}

Evogliptin is metabolized to 4(S)-hydroxyevogliptin (M2), 4(R)-hydroxyevogliptin (M3), 4-oxoevogliptin (M1), 4(S)-hydroxyevogliptin glucuronide (M4), and evogliptin N-sulfate (M5) in human liver preparations such as hepatocytes, microsomes and S9 fractions (Scheme 1). CYP3A4 played a major role in evogliptin hydroxylation to 4(S)-hydroxyevogliptin (M2) and 4(R)-hydroxyevogliptin (M3), with a minor contribution by CYP3A5. UGT2B4 and UGT2B7 are responsible for the glucuronidation of 4(S)-hydroxyevogliptin (M2) to 4(S)-hydroxyevogliptin glucuronide (M4). These results indicate that evogliptin metabolism may cause the interindividual differences in the pharmacokinetics of evogliptin in humans.

Acknowledgments: This work was supported by the National Research Foundation of Korea (NRF) grant funded by the Korea government (MSIP) (NRF-2014R1A2A2A01002582).

Author Contributions: H.-U.J. and J.-H.K. performed the experiments and data analysis, D.Y.L. and H.J.S. conceived and designed the experiments, H.S.L. was responsible for the study conception and design, data analysis, and writing of the manuscript.

Conflict of Interest: The authors declare no conflict of interest.

\section{References}

1. Olokoba, A.B.; Obateru, O.A.; Olokoba, L.B. Type 2 diabetes mellitus: A review of current trends. Oman Med. J. 2012, 27, 269-273.

2. Tiwari, P. Recent trends in therapeutic approaches for diabetes management: A comprehensive update. J. Diabetes Res. 2015, 2015, 340838, doi:10.1155/2015/340838.

3. Drucker, D.J. Therapeutic potential of dipeptidyl peptidase IV inhibitors for the treatment of type 2 diabetes. Expert Opin. Investig. Drugs 2003, 12, 87-100.

4. Ceriello, A.; Sportiello, L.; Rafaniello, C.; Rossi, F. DPP-4 inhibitors: Pharmacological differences and their clinical implications. Expert Opin. Drug Saf. 2014, 13 (Suppl. 1), S57-S68. 
5. Chen, X.W.; He, Z.X.; Zhou, Z.W.; Yang, T.; Zhang, X.; Yang, Y.X.; Duan, W.; Zhou, S.F. Clinical pharmacology of dipeptidyl peptidase 4 inhibitors indicated for the treatment of type 2 diabetes mellitus. Clin. Exp. Pharmacol. Physiol. 2015, 42, 999-1024.

6. Cho, J.M.; Jang, H.W.; Cheon, H.; Jeong, Y.T.; Kim, D.H.; Lim, Y.M.; Choi, S.H.; Yang, E.K.; Shin, C.Y.; Son, M.H.; et al. A novel dipeptidyl peptidase IV inhibitor DA-1229 ameliorates streptozotocin-induced diabetes by increasing beta-cell replication and neogenesis. Diabetes Res. Clin. Pract. 2011, 91, 72-79.

7. Kim, H.J.; Kwak, W.Y.; Min, J.P.; Lee, J.Y.; Yoon, T.H.; Kim, H.D.; Shin, C.Y.; Kim, M.K.; Choi, S.H.; Kim, H.S.; et al. Discovery of DA-1229: A potent, long acting dipeptidyl peptidase-4 inhibitor for the treatment of type 2 diabetes. Bioorg. Med. Chem. Lett. 2011, 21, 3809-3812.

8. Kim, M.K.; Chae, Y.N.; Kim, H.D.; Yang, E.K.; Cho, E.J.; Choi, S.H.; Cheong, Y.H.; Kim, H.S.; Kim, H.J.; Jo, Y.W.; et al. DA-1229, a novel and potent DPP4 inhibitor, improves insulin resistance and delays the onset of diabetes. Life Sci. 2012, 90, 21-29.

9. Kim, T.E.; Lim, K.S.; Park, M.K.; Yoon, S.H.; Cho, J.Y.; Shin, S.G.; Jang, I.J.; Yu, K.S. Evaluation of the pharmacokinetics, food effect, pharmacodynamics, and tolerability of DA-1229, a dipeptidyl peptidase IV inhibitor, in healthy volunteers: First-in-human study. Clin. Ther. 2012, 34, 1986-1998.

10. Gu, N.; Park, M.K.; Kim, T.E.; Bahng, M.Y.; Lim, K.S.; Cho, S.H.; Yoon, S.H.; Cho, J.Y.; Jang, I.J.; Yu, K.S. Multiple-dose pharmacokinetics and pharmacodynamics of evogliptin (DA-1229), a novel dipeptidyl peptidase IV inhibitor, in healthy volunteers. Drug Des. Dev. Ther. 2014, 8, 1709-1721.

11. Jung, C.H.; Park, C.Y.; Ahn, K.J.; Kim, N.H.; Jang, H.C.; Lee, M.K.; Park, J.Y.; Chung, C.H.; Min, K.W.; Sung, Y.A.; et al. A randomized, double-blind, placebo-controlled, phase II clinical trial to investigate the efficacy and safety of oral DA-1229 in patients with type 2 diabetes mellitus who have inadequate glycaemic control with diet and exercise. Diabetes Metab. Res. Rev. 2015, 31, 295-306.

12. Zanger, U.M.; Schwab, M. Cytochrome P450 enzymes in drug metabolism: Regulation of gene expression, enzyme activities, and impact of genetic variation. Pharmacol. Ther. 2013, 138, 103-141.

13. Rowland, A.; Miners, J.O.; Mackenzie, P.I. The UDP-glucuronosyltransferases: Their role in drug metabolism and detoxification. Int. J. Biochem. Cell Biol. 2013, 45, 1121-1132.

14. Murray, M. Role of CYP pharmacogenetics and drug-drug interactions in the efficacy and safety of atypical and other antipsychotic agents. J. Pharm. Pharmacol. 2006, 58, 871-885.

15. Vincent, S.H.; Reed, J.R.; Bergman, A.J.; Elmore, C.S.; Zhu, B.; Xu, S.; Ebel, D.; Larson, P.; Zeng, W.; Chen, L.; et al. Metabolism and excretion of the dipeptidyl peptidase 4 inhibitor $\left[{ }^{14} \mathrm{C}\right]$ sitagliptin in humans. Drug Metab. Dispos. 2007, 35, 533-538.

16. McGraw, J.; Waller, D. Cytochrome P450 variations in different ethnic populations. Expert Opin. Drug Metab. Toxicol. 2012, 8, 371-382.

17. Klein, K.; Zanger, U.M. Pharmacogenomics of cytochrome P450 3A4: Recent progress toward the "missing heritability" problem. Front. Genet. 2013, 4, 12, doi:10.3389/fgene.2013.00012.

18. Werk, A.N.; Cascorbi, I. Functional gene variants of CYP3A4. Clin. Pharmacol. Ther. 2014, 96, 340-348.

19. Deng, X.Y.; Wang, C.X.; Wang, X.D.; Bi, H.C.; Chen, X.; Li, J.L.; Huang, M. Genetic polymorphisms of UGT1A8, UGT1A9, UGT2B7 and ABCC2 in Chinese renal transplant recipients and a comparison with other ethnic populations. Die Pharm. 2013, 68, 240-244.

20. Miners, J.O.; McKinnon, R.A.; Mackenzie, P.I. Genetic polymorphisms of UDP-glucuronosyltransferases and their functional significance. Toxicology 2002, 181, 453-456.

Sample Availability: Not Available.

(C) 2015 by the authors; licensee MDPI, Basel, Switzerland. This article is an open access article distributed under the terms and conditions of the Creative Commons by Attribution (CC-BY) license (http://creativecommons.org/licenses/by/4.0/). 